\title{
Mercadeo, comunicación y artes, facultad construida con calidad educativa y calidez humana
}

Estas líneas las quiero dedicar a quienes de una u otra manera ayudaron a construir el proyecto educativo que es hoy la Facultad de Mercadeo, Comunicación y Artes de la Institución Universitaria Politécnico Grancolombiano.

De nuestros alumnos y egresados hablaré en otro momento, porque son tantos y con tanto reconocimiento profesional y laboral que merecen espacios propios en varias ediciones de Poliantea. También quisiera referirme específicamente a nuestros docentes, con la intención de no olvidar a quienes han llevado este ideal a las aulas y han ayudado a construir proyectos de vida felices y exitosos.

Basado en lo anterior, estas líneas las dedicaré a los responsables de la creación, el seguimiento, el fortalecimiento y la consolidación de los programas académicos de la Facultad, es decir, a quienes en calidad de decanos o directores de programa hacen posible la realidad académica de hoy.
Empiezo, entonces, por nuestro actual rector y primer decano de la entonces Facultad de Mercadeo y Publicidad, economista Jurgen Chiari, quien consolidó el programa tecnológico y creó el ciclo profesional en Mercadeo y Publicidad, los cuales en sus treinta años de funcionamiento han alcanzado no solo el reconocimiento profesional y laboral, sino dos veces la acreditación de alta calidad por parte del Ministerio de Educación Nacional y la acreditación internacional con la International Advertising Association (IAA).

A él debemos la integración del mercadeo y la publicidad en un solo programa y la conformación de la primera planta docente, toda ella con un alto reconocimiento en el medio publicitario y de mercadeo colombianos, con nombres como Jorge Molina Villegas, Socorro Jaramillo Velásquez y Daniel Ronderos Lobo, entre otros.

Sucedió a Jurgen en el cargo de decano de Mercadeo y Publicidad 
la abogada Juanita Michelsen Niño, quien por cerca de quince años lideró los procesos de revisión y reestructuración académica, inició el desarrollo de acreditación nacional e internacional, generó los primeros proyectos de investigación y proyección social yle dio la categoría y el reconocimiento que el programa de Mercadeo y $\mathrm{Pu}$ blicidad hoy mantiene.

Fue ella quien, con su equipo de trabajo, entre los que se destacan José Ricardo Franco, Diana Forero Rodríguez, José Tiusaba Ariza (q. e. p. d.), Edilma Pineda de Marín, Edgar Gualteros Rincón, Nora Ramírez Herrera y Mónica Baquero Gaitán, quienes crearon, entre otros proyectos, el Centro de Gestión de Información, que posteriormente diera origen a lo que hoy es el Departamento de Investigación de la Institución, la Agencia de Publicidad Estudiantil Trompo, que hoy presta servicios a toda la comunidad institucional en sus campañas de información y de bien público, y realizaron el Primer Encuentro de Universidades y Escuelas de Publicidad y Mercadeo de América Latina, del cual se originó el programa de movilidad internacional para todos los estudiantes de la Institución.

A los anteriores, se unen los nombres de Carlos Augusto García López y de Daniel Caicedo Ortiz, creadores de los programas de Comunicación Social-Periodismo y Profesional en Medios Audiovisuales, respectivamente, programas que juntamente con los de Mercadeo y $\mathrm{Pu}$ blicidad, Diseño Gráfico, Artes de la Escena, Diseño de Modas y Diseño Industrial, hoy conforman la Facultad de Mercadeo, Comunicación y Artes.

Ellos fueron los primeros decanos de la que inicialmente fue la Facultad de Ciencias de la Comunicación y Artes y quienes integraron los programas en una nueva unidad académica centrada en la comunicación, organizada curricularmente en créditos académicos, con procesos de movilidad internacional y de calidad, inicialmente para la presentación de los informes para el Registro Calificado ante el Ministerio de Educación Nacional, y luego para comenzar los procesos de autoevaluación con fines de acreditación de alta calidad.

A García López le corresponde ser el artífice de la reestructuración curricular de los programas de pregrado de la Facultad con planes de estudio definidos por los bloques temáticos institucional, de facultad, de programa y electivo, elaborados para dar una mayor flexibilidad a los currículos, brindar oportunidades de doble título de pregrado y destinar 
el quinto año para que lo estudiantes pudieran cursar un programa de posgrado en el nivel de especialización.

Años atrás, Carlos Augusto había sido el creador y primer decano de la entonces Facultad de Comunicación Social, con su programa en Comunicación Social-Periodismo y los énfasis en Comunicación Organizacional y en Periodismo, que, años más tarde, darían vida a los nuevos proyectos de práctica, como Polimedios, productora de contenidos audiovisuales institucionales; Sala Contacto, productora de contenidos multimediáticos informativos, y el Departamento Institucional de Comunicación, con sus direcciones de Comunicación Digital, Producción de Contenido y Jefatura de Prensa Institucional.

Caicedo Ortiz, por su parte, es el artífice de la creación del programa profesional en Medios Audiovisuales con sus énfasis en Cine, Diseño Gráfico, Fotografía, Sonido y Televisión y, con este, del Centro de Medios Audiovisuales, unidad de práctica permanentemente dotada con las últimas tecnologías para la realización y producción de los diferentes medios que integran el programa y para la prestación de diferentes servicios audiovisuales a toda la comunidad de la Institución.
A ellos les correspondió conducir los procesos de reestructuración de los programas de pregrado que arriba mencionamos, la implementación del modelo de educación virtual y la revisión y reestructuración de los programas de posgrado, que hoy hacen parte de los servicios de la Facultad de Mercadeo, Comunicación y Artes.

Por último, y por ello no menos importante, debo hacer un especial reconocimiento a Claudia Michelsen Niño y John Jaime Marín Niño, quienes desde la Escuela de Posgrado impulsaron los programas de Especialización en Gerencia de Mercadeo y Especialización en Comunicación Corporativa, con los cuales se iniciaron los programas de posgrado de la Facultad, en la que se ofrece la Especialización en Gerencia de Mercadeo en modalidad virtual y la Maestría en Gerencia Estratégica de Mercadeo en modalidad presencial.

En otro momento hablaremos del nuevo equipo humano de la Facultad y de los nuevos programas de pregrado y posgrado, presenciales y virtuales, que se integran en la Escuela de Diseño y de Servicios BPO (business process outsourcing), que generan la nueva área de Artes de la Escena y que dan origen al primer programa 
superior de posgrado con la Maestría en Gerencia Estratégica de Mercadeo.

Es muy corto el espacio para detallar todas las iniciativas y logros que mis antecesores lograron en estos treinta años de servicio de la Facultad y sus programas, es muy mala la memoria para integrar a todos los equipos de trabajo que acompañaron a cada uno de estos líderes, son muy pequeñas las manos, pero grande el corazón, para decirles a todos y cada uno de ellos, en nombre propio, en nombre de los estudiantes, de los egresados, de los empresarios, de los receptores de práctica y del medio del mercadeo, la publicidad, la comunicación y los medios audiovisuales, gracias por que más que una gestión su obra fue un compromiso, por que más que administrar programas ustedes son los artífices de muchos proyectos de vida que contribuyen decididamente al progreso social, cultural y empresarial del país.

Este reconocimiento no estaría completo sin tener en cuenta el aporte de nuestros rectores en estas tres décadas de funcionamiento, valga pues hacer un especial reconocimiento a César Tulio Delgado Hurtado, Pablo Michelsen Niño y Fernando Dávila Ladrón de Guevara, sin cuyo apoyo y orientación no habríamos llegado al lugar de prestigio, calidad y reconocimiento que hoy tiene la Facultad y todos sus programas en los medios académico y empresarial del país.

Sergio Oswaldo Hernández Muñoz Bogotá, 6 de octubre de 2014 